\title{
5 Years Old Girl With Stab Wound
}

\section{IJafar Ghobadi', Samad Shams Vahdati' Mohammad Naghavi-Behzad²}

${ }^{1}$ Emergency Department, Tabriz University of Medical Science, Tabriz/iran

23. liver \& Gastrointestinal Disease Research Center, Tabriz University of Medical Sciences,

Tabriz, Iran

Child abuse is a kind of misuse or neglect which is happened on children under 18 years old. It includes all kinds of physical or emotional abuse, sexual abuse, negligence, delinquency, economic and any kind of exploitation which lead to real or potential damage to health, survival, growth, or dignity of child. Patient was a five-year-old girl who was brought to emergency service of Sina Hospital because of a penetrating wound in upper abdomen caused by her older sister. There was visceral perforation and it was repaired.

Keywords: child abuse, stab wound, neglect 


\section{Introduction:}

Child abuse is a kind of misuse or neglect which is happened on children under 18 years old. It includes all kinds of physical or emotional abuse, sexual abuse, negligence, delinquency, economic and any kind of exploitation which lead to real or potential damage to health, survival, growth, or dignity of child. Child abuse is a global concern, but there is no real statistical data about how frequent it is worldwide. As WHO report, Annually about 31000 cases of domestic murder are committed on children under 15 years old 1 .

Physical damages or traumas are most common cause of child abuse that physicians are dealing with. Three common mechanisms of abdominal trauma in children are motor vehicles (61.27\%), child abuse (15.75\%), and fall (13.59\%). Comparing with fall, child abuse independently entails 6 times higher mortality rate in hospitalized patients ${ }^{2}$.

Here in, a five-year-old female case who had penetrating abdominal trauma is introduced and discussed.

\section{Case Presentation:}

Patient was a five-year-old girl who was brought to emergency service of Sina Hospital because of a penetrating wound in upper abdomen caused by her older sister (Figure 1). As her sister claims, the girl suffered penetrating wound in that area about half an hour before referring, as a result of hitting a knife into her abdomen after her fall when she was playing. The child seemed very frightened, had anguished glances, and was completely silent. Also she was looking at her 23-year-old sister fearfully. When she was being asked, her sister was answering. She was the second child in her family. Often she was supported by her sister. Her mother was under drug treatment for many years because of depression and personality disorders. Her father was a part time worker and they live in suburb of Tabriz.

Since she was so frightened and due to her sister's paradoxical answers, the child was asked about accident when she was carried to operation room and before anesthesia, and it was found that she was stabbed by her mother.

At referring rime she was totally aware and $G S C=15$. She was not pale. Her vital signs were stable. In abdomen examination laceration was observed in upper left of abdomen whose length was $1 \mathrm{~cm}$. Wound place has not active bleeding. Abdomen was soft when it was being touched and it was tenderness around the wound. In a complete examination there were observed signs of superficial wounds on her left wrist and chest as well as bruises on back and hips. There was no symptom of wound, hematoma, and bruises in genital area as a sign of sexual violence or abuse.

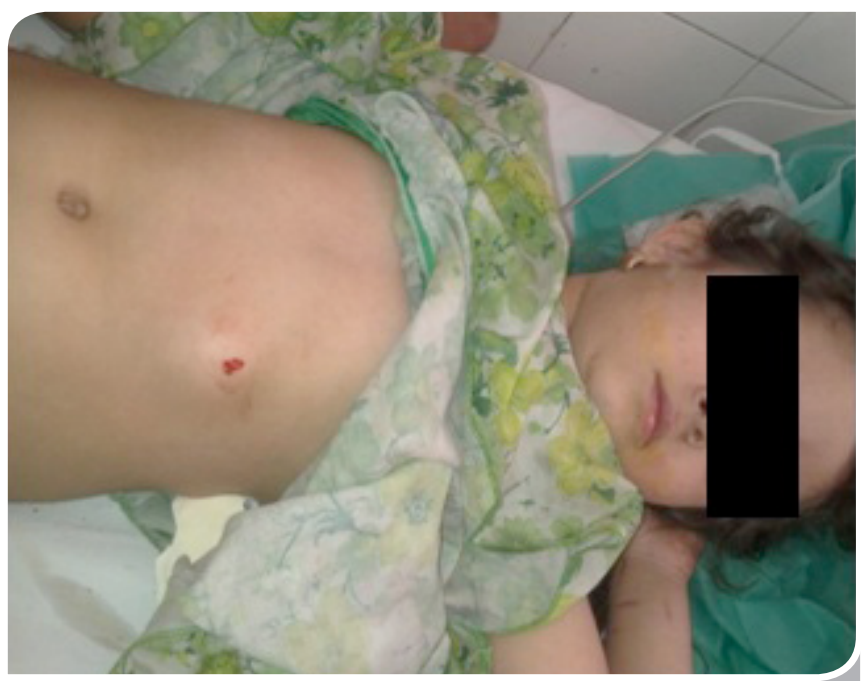

Figure 1: Patient was a five-year-old girl who had a penetrating wound in upper abdomen caused by her older sister.

In order to examine status of the child it was asked for $\mathrm{CBCl}$ diff, BUN/Cr, PTT/INR, $\mathrm{Na}$, and $\mathrm{K}$ tests and all were normal. Patient had eaten her last meal about 4 hours before trauma.

\section{Diagnosis and Treatment}

Chest X-Ray air revealed presence of air under diaphragm showing rupture of hollow viscera. Considering anatomical area of wound, there was a probability of gastric rupture (figure 2 ). After diagnosing actions the child was transferred to operation room after P\&D under general anesthesia, LUQ of abdominal wall was opened by transverse incision. There was about 200 cc of gastric secretions inside abdomen which was suctioned. In examining anterior gastric wall rupture was evident in Body part and was restored. Pancreas, posterior gastric wall, transverse colon, splenic flexure, descending colon, small intestine, liver, and spleen all were normal. Wound of anterior gastric wall was restored in two layers. Then peri- 
toneal washing was done and abdominal wall was restored after counting instruments.

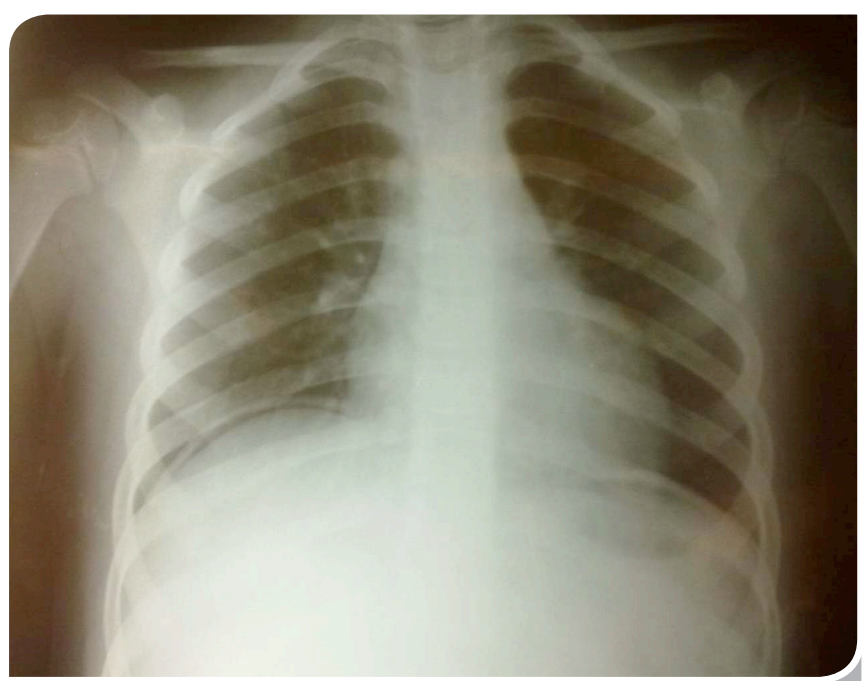

Figure 2: Chest X-Ray air revealed presence of air under diaphragm showing rupture of hollow viscera.

\section{Discussion}

Abdominal trauma is divided into two blunt and penetrating groups and the most of the children with abdominal trauma suffer from blunt trauma. One of traumatic mechanisms could be child abuse. Abdominal injury is the second prevalent mortality cause in children as a result of child abuse and is responsible for $6 \%$ to $8 \%$ of physical abuses ${ }^{3,4}$. Just $1 \%$ of hospitalizations in cases of child abuse are related to abdominal injuries ${ }^{5,6,7}$. Mortality rate for this population is among $40 \%$ to $50 \%$. Most of abdominal traumas lead to solid abdominal viscera damage such as in organs like spleen, liver, and kidney ${ }^{10,11}$. The low percentage of traumas leads to damage to hollow abdominal viscera ${ }^{12,13}$. Gastric rupture occurs in rare cases ${ }^{14,15,16,17,18}$ and if it is not diagnosed on time, it can lead to septic shock and death ${ }^{19}$. The first gastric rupture case resulted by trauma was reported by Pinacastell in $1922^{20}$. Rare cases of gastric damages are result of physical abuse ${ }^{21}$. The factors that could be the reason for rare gastric damages among other hollow viscera include: high mobility rate, being in protected place, thick wall, and being empty in the most cases ${ }^{22}$. Although it is probable for lesions' level to seem negligible in primary examinations of abdominal area, but more investigations could clearly show the depth of damage resulting in injury of abdominal viscera. In more than $65 \%$ of examinations in child abuse cases ${ }^{22}$ it is possible to observe skin pricks, ocular bleedings, and various fractures in different parts of child's body ${ }^{24}$. High mortality rate caused by abdominal trauma in children shows the necessity for rapid diagnosis.

Memoir has an important role in child abuse cases but in such cases, due to legal and social consequences of such behaviors, we cannot and should not trust on memoirs provided by child's relatives and parents. In such situations, clinical examinations on admission, and attraction of child's trust, and even paying attention to his/her mental and psychological status could certainly be so helpful.

As it was observed in this case, psychological status of parents, socio-economical status, and living in suburbs are of reasons that could be resulted in child's psychological abuse and even his/her harassment by parents. In such cases not only treatment of physical damages should be considered, but also other probable damages should be prevented. Social supports, psychiatric consultations and assistance, and various trainings for parents should be considered. Also after treatment of child, helshe should be monitored for a long period and necessary investigations should be conducted to deal with child's psychological status. 


\section{References}

1. http://www.who.int/mediacentre/factsheets/fs150/en

2. Matthew Trokel, Carla DiScala, Norma C. Terrin, Robert D. Sege. Blunt Abdominal Injury in the Young Pediatric Patient: Child Abuse and Patient Outcomes. child maltreatment 2004; 9: 1 111-117. doi: $10.1177 / 1077559503260310$

3. Cooper A, Floyd T, Barlow B, et al. Major blunt abdominal trauma due to child abuse. J Trauma. 1988;28(10):1483-1487

4. Ledbetter DJ, Hatch El Jr, Feldman KW, Fligner CL, Tapper D. Diagnostic and surgical implications of child abuse. Arch Surg. 1988;123(9):1101-1105

5. Cooper A, Thomas T, Barlow B, et al. Major blunt abdominal trauma due to child abuse. J Trauma 1988; 28: 1483-87.

6. Caniano DA, Beaver BL, Boles ET. Child abuse: an update on surgical management in 256 cases. Ann Surg. 1986;203:219-224

7. Rothrock SG, Green SM, Morgan R. Abdominal trauma in infants and children: prompt identification and early management of serious and lifethreatening injuries. Part 1: injury patterns and initial assessment. Pediatr Emerg Care. 2000;16:106-115

8. Cooper A, Floyd T, Barlow B, et al. Major blunt abdominal trauma due to child abuse. J Trauma. 1988;28:483-1487.

9. Helfer ME, Kempe RS, Krugman RD. The Battered Child. 5th ed. Chicago, IL: The University of Chicago Press; 1997:205-206.

10. Philippart, A. I., "Blunt Abdominal Trauma in Childhood." Surgical Clinics of North America,Vol. 57, No. 1, Feb. 1977, pp. 151-163.

11. Asch, M. J., Coran, A. G., and Johnston, P. W., "Gastric Perforation Secondary to Blunt Trauma in Childhood," Journal of Trauma, Vol. 15, No. 3. March 1975, pp. 187-189.

12. Dickinson, S. J., Shaw, A., and Santulli, T. V., "Rupture of the Gastrointestinal Tract in Children by Blunt Trauma," Surgely GynecoloD, \& Obstetrics, Vol. 130, No. 4, April 1970,pp. 655-657.
13. 13. Semel, L. and Fritelli, G., "Gastric Rupture from Blunt Abdominal Trauma," New York State Journal of Med\&ine, Vol. 81, No. 6, May 1981, pp. 938-939.

14. Yajko, R. D.. Seydel, F., and Trimble. C., "Rupture of the Stomach from Blunt Abdominal Trauma," Journal of Trauma, Vol. 15. No. 3, March 1975, pp. 177-183.

15. Case ME, Nanduri R . Laceration of the stomach by blunt trauma in a child: a case of child abuse. J Forensic Sci.1983;28(2):496-501.

16. Leone RJ Jr, Krasna IH. 'Spontaneous' neonatal gastric perforation: is it really spontaneous? J Pediatr Surg. 2000;35(7):1066-9.

17. McCort J,Vaudagna J.Visceral injuries in battered children. Radiology. 1964;82:424-428

18. Schechner SA, Ehrlich FE.Case reports. Gastric perforation and child abuse.J Trauma.1974;14(8):723-725

19. Case ME, Nanduri R .Laceration of the stomach by blunt trauma in a child: a case of child abuse. J Forensic Sci.1983;28(2):496-501.

20. Piancastelli, A., "Rupture of Stomach from Contusion, " La RiJorma Medica, Vol. 3, No. 4, Oct, 1922, pp. 1038-1039.

21. Case ME, Nanduri R .Laceration of the stomach by blunt trauma in a child: a case of child abuse. J Forensic Sci.1983;28(2):496-501.

22. Yajko, R. D.. Seydel, F., and Trimble. C., "Rupture of the Stomach from Blunt Abdominal Trauma," Journal of Trauma, Vol. 15. No. 3, March 1975, pp. 177-183.

23. Ledbetter DJ, Hatch El, Feldman KW, et al. Diagnostic and surgical implications of child abuse. Arch Surg1988;123:1101-5

24. Merten DF, Carpenter BLM. Radiologic imaging of inflicted injury in the child abuse syndrome. Pediatr Clin N Am1990;37:815-37 